\title{
Lateralized Functions in the Dog Brain
}

\author{
Marcello Siniscalchi *, Serenella d'Ingeo and Angelo Quaranta \\ Department of Veterinary Medicine, Section of Behavioral Sciences and Animal Bioethics, \\ University of Bari “Aldo Moro", 70121 Bari, Italy; serenella.dingeo@uniba.it (S.I.); \\ angelo.quaranta@uniba.it (A.Q.) \\ * Correspondence: marcello.siniscalchi@uniba.it; Tel.: +39-080-544-3948
}

Academic Editor: Lesley J. Rogers

Received: 21 March 2017; Accepted: 10 May 2017; Published: 13 May 2017

\begin{abstract}
Understanding the complementary specialisation of the canine brain has been the subject of increasing scientific study over the last 10 years, chiefly due to the impact of cerebral lateralization on dog behaviour. In particular, behavioural asymmetries, which directly reflect different activation of the two sides of the dog brain, have been reported at different functional levels, including motor and sensory. The goal of this review is not only to provide a clear scenario of the experiments carried out over the last decade but also to highlight the relationships between dogs' lateralization, cognitive style and behavioural reactivity, which represent crucial aspect relevant for canine welfare.
\end{abstract}

Keywords: dog; lateralization; emotion; behaviour; physiology

\section{Introduction}

Brain hemispheres specialise to process and analyse information in an asymmetrical way is a phenomenon widely reported in the animal kingdom [1,2] and, as shown by the increasing scientific study over the last decade, it is now well manifested also in canine species. Based on findings derived from experiments carried on different animal models, clear evidence exists that basic lateralized neural mechanisms are very similar across vertebrate brains with a specialisation of the left hemisphere in the control of routine behaviours, responding to features that are invariant and repeated, and with the specialisation of the right hemisphere in detecting novelty (unexpected stimuli) and in the expression of intense emotions, such as aggression and fear [3,4].

In this review, our first aim is to provide a comprehensive overview of the experiments carried out in dogs providing extensive evidence of hemispheric asymmetries in function, structure and behaviour. Our second aim in this paper is to analyse lateralized patterns specifically involved in emotional processing by the dog brain and how the study of emotional lateralization could represent a valid and interesting tool to contribute to the improvement of canine welfare and management.

In dogs, deepening the knowledge of cerebral lateralization with particular regard to emotional processing is particularly interesting since behavioural asymmetries which indirectly reflect lateralized cognitive processing of emotions can be easily detected (e.g., paw preference, nostril use, and tail wagging) and can give insight into the different valences of an emotion felt by the animal. The latter is crucial not only for a better understanding of canine cognition but also for the improvement of dogs' training and handling during several activities within the human community (e.g., animal-assisted therapy, police and rescue work, and guides for vision impaired people).

\section{Sensory Lateralization}

The complementary specialisation of dogs' brain hemispheres is clearly apparent at different sensory levels, including vision [5], hearing [6-10] and what is considered to be the most relevant sensory domain for canine species, namely olfaction [11,12]. 
Asymmetries of dogs' visual sensory channels have been observed by studying their asymmetrical head-turning response to bidimensional visual stimuli presented during feeding behaviour [5]. The experimental set-up consisted of the presentation of black silhouette drawings of different animal models (a dog, a cat and a snake) to the dog's right and left visual hemifields using two retro-illuminated panels. When stimuli were presented at the same time in the two visual hemifields, dogs preferentially turned the head with their left eye leading in response to alarming stimuli (the snake silhouette that is considered to be an alarming stimulus for most mammals [13] or the cat silhouette displaying a defensive threat posture). Given that, in dogs, neural structures located in the right hemisphere are mainly fed by inputs from the left visual hemifield and vice versa (crossing of fibres at the optic nerve level is 75\% [14]), left head turns in response to threatening stimuli are consistent with the specialisation of the right side of the brain for expressing intense emotion including fear (snake) and aggression (cat with an arched lateral displayed body and erected tail). The latter specialisation of the right hemisphere has been reported in several animal models (reviewed in [1,2]).

It is interesting to note that left head turns (right hemisphere activation) lead to shorter latencies to react and longer latencies to resume feeding (i.e., higher emotional response). Moreover, during monocular presentation, higher responsiveness to stimuli presented in the left visual hemifield was observed, and this was irrespective of the type of stimulus. Overall, these results support the hypothesis that in canine species, as well as in other mammals, the neural sympathetic mechanisms controlling the "fight or flight" behavioural response are mainly under the activation of the right hemisphere [15]. In dogs, it is interesting to note that both in vivo [16] (Computed Tomography (CT) brain scanning) and post mortem techniques [17] have revealed a right-biased hemispheric asymmetry with the right hemisphere greater than the left; the latter could reflect the right hemisphere specialisation for intense emotional activities like fight or flight reactions, which are related to aggressive and defensive-escape behaviours.

As in dogs, a number of animals exhibit aggressive and defensive behaviours when the right hemisphere is active. Chicks, for example, respond strongly to a potential predator (silhouette of a predatory bird) seen in their left visual field (right hemisphere) $[18,19]$ ); very similar results were reported in toads, which showed stronger avoidance responses when a model snake was presented on their left side than when it was on their right side [20]. In domestic animals, horses approached by a potential threatening stimulus (a human opening an umbrella) reacted more (i.e., moving further away) when the approach was from their left side than when it was from their right side [21].

There is now evidence that the auditory sensory system in the dog brain also works in an asymmetrical way depending on the type of acoustic stimulus [6,8,9]. Specifically, during feeding behaviour, dogs' head orienting responses to different sounds played at the same time from two speakers placed symmetrically with respect to the subjects' head were recorded [6] (see Figure 1A). When thunderstorm playbacks were presented, dogs consistently turned the head with their left ear leading and, given that the direction of the head turn is an unconditioned response indicating a contralateral hemispheric advantage in attention to the auditory stimulus [22], this result supported the right hemisphere specialization in processing alarming stimuli. In a similar way to what has been previously reported about vision, in this experimental condition, left-head orienting turns also led to longer latencies to resume feeding from the bowl. On the other hand, dogs consistently turned the head with their right ear leading in response to playbacks of canine vocalizations ("disturbance" and "isolation" calls) supporting the role of the left hemisphere in the analysis of familiar conspecific calls, as reported in other species (non-human primates [23], horses [24], cats [25] and sea lions [26]). Nevertheless, in dogs, conspecific vocalizations are not always processed by the left hemisphere, since the right hemisphere is used for processing vocalizations when they elicit intense emotion [6,7]. 


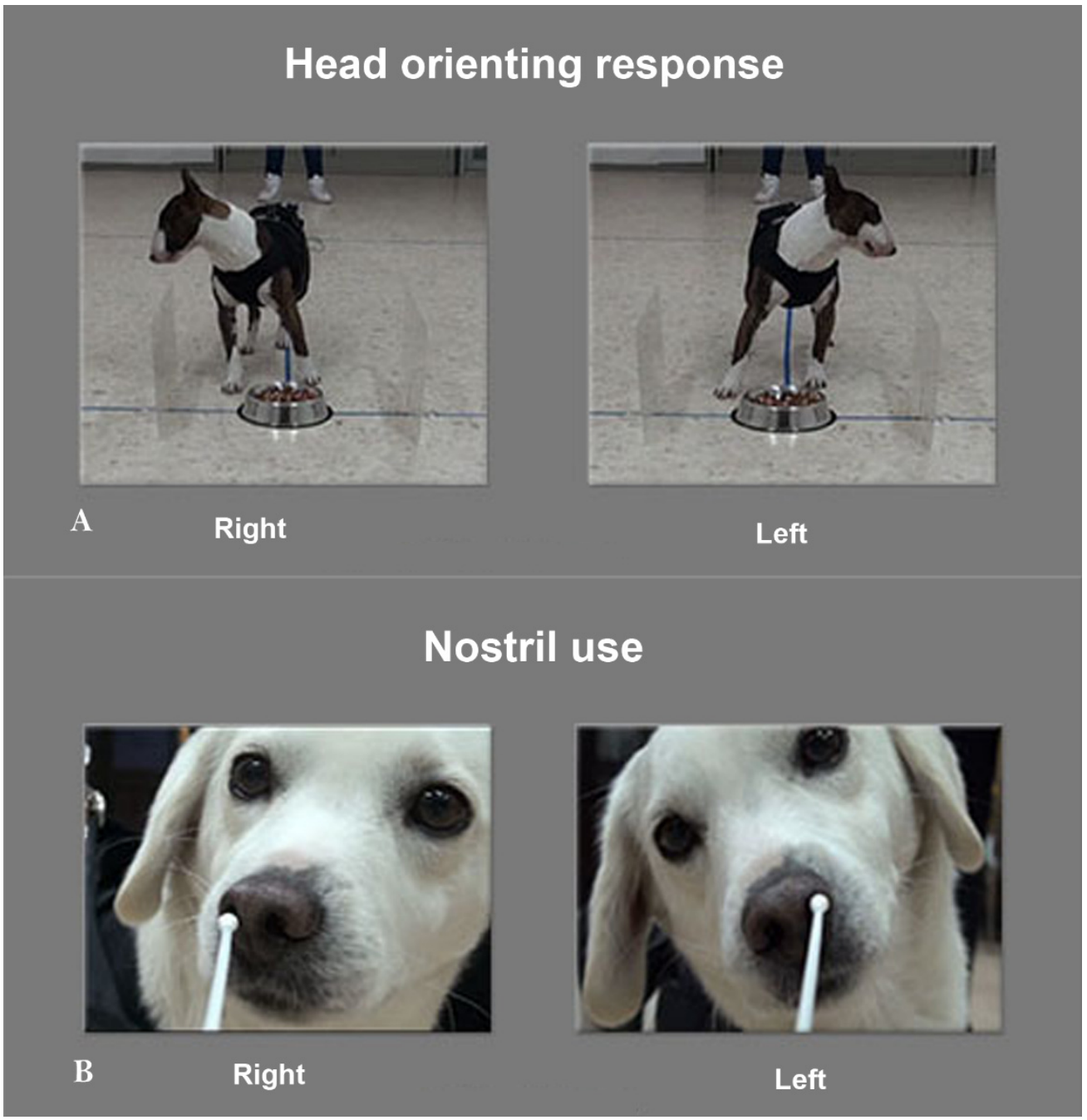

Figure 1. Behavioural techniques used to study functional lateralization in dogs: (A) head-orienting response used to study auditory lateralization; and (B) left and right nostril use during sniffing different olfactory stimuli.

In dogs, the left hemisphere advantage in processing vocalizations of familiar conspecifics seems dependent on the calls' temporal features, since the presentation of the reversed version of the same canine call caused the loss of the right bias in the head turning response [27].

Head orienting response methods have been used in dogs to study possible lateralized neural mechanisms in processing human speech [8]. Results revealed that dogs consistently turned their head to the right during presentation of human spoken commands with artificially increased segmental cues (i.e., higher salience of meaningful phonemic components); moreover, a significant left-turning bias was observed in response to manipulated commands with increased supra-segmental vocal cues (i.e., higher salience of intonation component). These results have been confirmed by recent neuroimaging studies and overall suggest a convergent lateralized brain specialisation between canine and human species for processing speech [9].

Regarding olfaction, asymmetries in nostril use have been observed during free sniffing behaviour of odorants that differ in terms of emotional valence [11,28]. Briefly, cotton swabs installed on a digital video camera were used to present odorants to dogs (see Figure 1B). The camera was installed on a tripod in the centre of a large silent room. A frame-by-frame analysis of nostril use video footages revealed a clear right nostril bias during sniffing of clearly arousing odours for dogs (e.g., adrenaline and veterinary sweat). Given that, in dogs, the olfactory nervous fibres, which drive 
odour information from peripheral receptors to the olfactory cortex, are uncrossed, right nostril use indicates a prevalent right hemisphere activation [29]. The latter was consistent with the previously reported right hemisphere involvement in analysing alarming/threatening stimuli and had direct implication for dogs' welfare and training since, for example, the constant use of the right nostril during olfactory inspection of a human being could reveal an increased arousal state of the animal, even in the absence of clear behavioural signs (this could be useful in those activities like animal-assisted therapy in which dogs must possess advanced behavioural control skills in order to help them handle high arousal situations and consequently it is not always easy to detect stress increase directly from behavioural signs).

When non-aversive stimuli were presented (e.g., food, lemon, and canine vaginal secretions), right nostril use was observed only during the first presentations indicating the initial involvement of the right hemisphere in the analysis of novelty (this bias was not evident for initial sniffing of food probably because of its reduced valence as a novel stimulus). Furthermore, a shift from the right to the left nostril use was observed with repeated stimulus presentations, indicating the prevalent control of sniffing behaviour by the left hemisphere when routine responses to odour stimuli emerge as a result of familiarization $[1,2,30,31]$. Left hemisphere specialisation in routine tasks has been observed in pigeons [32], wild stilts [33], toads [34] and chickens [35]. In the latter case, during a routine task of finding food, chicks using the right eye (left hemisphere) and not the left eye learn to find food grains scattered on a back-ground of distracting pebbles (similar to the grains).

There is now evidence that dogs' olfaction works in an asymmetrical way for processing both conspecific and heterospecific odours collected during different emotional events [12]. In particular, during sniffing of canine odours collected in a stressful situation (i.e., an "isolation" situation in which dogs were isolated from their owners in an unfamiliar environment), a consistent use of the right nostril was observed (right hemisphere activity). Moreover, when human odorants were presented to dogs, a significant left-nostril bias (left hemisphere activation) was reported to sniff olfactory stimuli collected from humans during a fearful situation (emotion-eliciting movies) and physical stress. The observed opposite nostril use pattern in response to conspecific and heterospecific odorants suggests that dog's olfaction uses different sensory pathways to extract emotional cues from canine and human chemosignals. Furthermore, an interesting hypothesis about the left nostril use during sniffing at human sweat collected during a fear situation and physical stress is that these heterospecific chemosignals (probably produced during the escape behavioural response to a predator) could elicit dogs' prey drive (i.e., approaching behavioural tendencies) to the stimuli through the selective activation of the left hemisphere. The evidence that, in dogs [36], as in other animal models (e.g., toads [34] and birds [33]), neural structures on the left side of the brain are involved in the control of predatory behaviour supports this hypothesis.

\section{Paw Preferences}

Asymmetries of motor functions have been widely reported in various vertebrate and invertebrate species, including the dog $[1,2]$. There is now a growing body of literature on motor lateralization in dogs, focused mainly on behavioural lateralization in the form of forelimb preferential use. In recent studies, paw preference has been assessed using several tasks: removal of a adhesive plaster from the eye [17,37] or of a piece of tape from the nose [38-42], removal of a blanket from the head [43], retrieval of food [44,45] from a toy object (namely the "Kong", see Figure 2) [46-50] or a metal can [43], paw-shaking [43], first foot placed forward to depart from a standing or sitting position [49,51] or during a run [52] and stabilization of a ball [39] and hindlimb raising behaviour during urination [53]. 


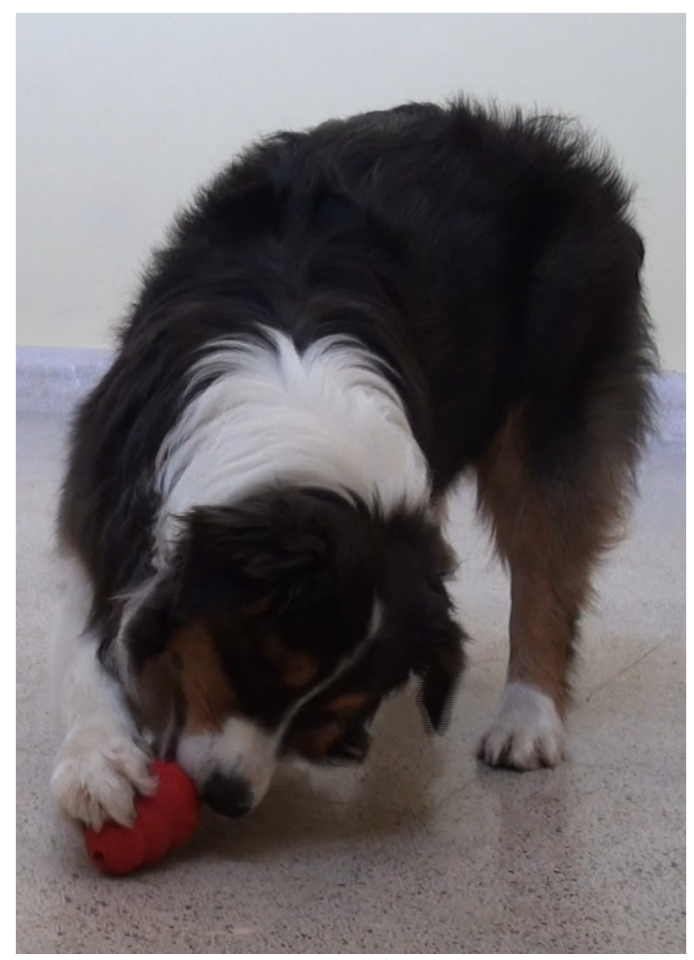

Figure 2. Motor lateralization: right paw use during stabilization of a food object (namely the "Kong").

The existence of motor asymmetries at a population level is currently a subject of wide debate. It has been reported in several species, including humans [54], non-human primates [55,56], rats [57], humpback whales [58] and common European toads [59] but studies on other animals, as for example marmosets [60], sheep [61,62], cats [63] and horses [64,65], has shown a motor bias only at the individual-level. However, the same species may also display a limb preference at the level of population or at the individual level depending on the task, as found in monkeys [66,67], cats [68] and sheep [69].

Motor lateralization in dogs is stable between breeds and over time $[41,46]$ but variable between sexes. Although a few studies have reported an association between paw preference and sex at a population level but in opposite directions, with males showing a left-paw and females a right-paw preference $[29,43,47]$, this seems to be inconsistent with other findings, which describe no population bias $[17,39,41,46,51]$. These conflicting results suggest that sex hormone status could be influential on the development of individual motor laterality but further investigations are necessary to accurately determine if this is the case.

There have been several recent studies that revealed an interesting association between emotional functioning and limb preference in animals, including dogs. It is well established that in primates motor bias is associated with differences in the behaviour of individuals and their emotional states. In particular, left-handed/pawed animals displayed more fear responses, higher stress level and reactivity than right-handed/pawed animals $[4,70,71]$. The latter, instead, were more likely to approach new objects and showed more social behaviours to capture a prey (chimpanzees: [72], marmosets: [73,74]). These behavioural differences match the known specialization of the hemisphere involved in the control of motor functions (contralateral to the preferred limb). Therefore, the limb preferential use could be indicative of the subject's personality type and its likelihood of expressing a positive or negative emotional functioning. Recent studies have reported indeed that left-handed marmosets have a negative cognitive bias compared to right-handed marmosets, which display a positive cognitive bias [75]. Concerning dogs, Branson and Rogers [46] showed that dogs with weaker motor lateralization were more reactive when exposed to potentially threatening stimuli (thunderstorm 
and fireworks sounds) since they displayed more stressed behaviours than lateralized subjects. Dogs with stronger paw preference are otherwise more confident and relaxed in an unfamiliar environment and when presented with novel stimuli [76]; on the contrary, they are less able in a problem-solving task, to manipulate and explore a new object to obtain food than ambilateral subjects [76].

Given these findings, preferential limb use could be employed as a measure to assess vulnerability to stress and welfare risk in animals [4] and also in dogs. Consequently, it is essential to correctly categorize subjects as left- or right-pawed, choosing a motor test that provides reliable information about dogs' dominant paw, in order to make inference about dogs' dominant hemisphere and their ability to cope with stress. Wells et al. [48] recently investigated whether dogs use their dominant paw in the most common motor test employed in this species, namely the Kong test. They found that dogs use their non-dominant paw to stabilize the Kong to obtain food and their dominant paw for postural support. These findings need to be considered for correct implications on animals' welfare and emotional vulnerability.

Therefore, the evaluation of paw preferential use could provide notable information regarding a dog's predisposition to solve future behavioural problems or about its suitability for work. It has been demonstrated, indeed, that the direction of laterality is predictive of success in a Guide Dog Training Programme; in particular, right-pawed dogs were more successful in completing the training than left-pawed and ambilateral subjects [77].

Considering that behavioural differences in dogs' response to different situations are linked with motor lateralization and that dogs' temperament plays an important role in the selection of dogs (for working or adoptions), Schneider and colleagues [50] examined the relationship between paw preference and temperament. They found no differences between lateralized and non-lateralized dogs in the score obtained by a questionnaire completed by owners, aside from stranger-directed aggression scale, where lateralized subjects registered higher scores than the ambilateral ones. This may suggest the existence of a lateralized component in that particular type of aggressive response but further investigations are required. Moreover, recent findings show that behavioural signs of fear and distress displayed in a given situation and motor laterality are not associated with cortisol concentration in saliva samples [42].

However, it would be interesting in the near future to deepen our understanding of the relationship between motor laterality and emotional functioning since knowing the direction of paw preference of a dog we could correctly assess the strategy to be employed to preserve and improve its welfare.

Motor laterality is also associated with the analysis of visuospatial information, as we recently found in our research. Specifically, agility trained dogs with weaker paw preference were less attentive in performing agility exercises and displayed greater latency in the wave poles task (i.e., dogs' ability to work around pole obstacles that are secured in a straight line to a metal base) when the owner was positioned in its left visual field [78]. These results clearly show that stimuli with high emotional valence (the owner) could influence specific cognitive abilities, particularly when the right hemisphere processes them. In a more recent study, we reported that visuospatial attention is strictly related to motor lateralization since left-pawed dogs exhibited left visuospatial bias, right-pawed dogs a reversed rightward bias, while ambilateral dogs displayed no bias [79]. The existence of such a relationship has significant implications for animal welfare since it establishes a basis on which to develop new therapies for the rehabilitation of visual attention during pathological conditions (namely, unilateral spatial neglect); it could also help humans to improve canine training techniques, choosing the correct side to handle dogs and how to capture their attention easily.

The importance of paw preference assessment as a useful tool to preserve animal welfare derives also from the evidence of a direct relationship between dogs' motor laterality and immune response via an asymmetrical modulation exerted by the autonomic nervous system [38,80-82]. Right-pawed and left-pawed dogs exhibit different patterns of immune response, in particular the former displayed higher granulocytes percentage, number of $\gamma$-globulins [38], anti-rabies antibody titres and interferon 
gamma (IFN- $\gamma$ ) serum level [80] while the latter showed higher lymphocytes number [38] and higher expression of specific interleukin genes (IL-2 and IL-6) after immune challenge [81]. Furthermore, ambidextrous dogs exhibit a significantly higher increase of catecholamine levels after immunization with rabies vaccine than lateralized subjects [82].

The direction of dogs paw preference is also related to anatomical asymmetries of the brain. Aydınlığlu et al. [45] found a variation in callosal size, particularly in its posterior segment (namely the isthmus) that was larger in right-preferent dogs than left-pawed subjects. Post mortem analyses showed also morphological asymmetries in canine hippocampi, which is associated with both sex (males larger than females) and paw preference. Female left-pawed dogs showed indeed larger hippocampi than the right ones [44]. In light of this evidence, motor lateralization may be considered as a direct consequence of brain structural asymmetries that could be, more broadly the likely cause of cerebral specialization of functions.

\section{Tail-Wagging as a Tool to Study the Asymmetrical Representation of Emotional Processing in the Dog Brain}

Tail wagging represents an interesting model to study competition or cooperation between brain hemispheres in the control of behavioural response to emotional stimuli mainly for two reasons:

(1) Dogs move their tails in an asymmetrical way in response to different emotional stimuli [83].

(2) Studies on behavioural asymmetries associated with lateralized brain functions have usually focused on asymmetric use of paired organs (e.g., forelimbs) but not of a medial organ (i.e., the tail). In order to test asymmetries in tail wagging behaviour, family pet dogs of mixed breeds were placed in a large rectangular wooden box with an opening on the centre of one of its shorter side to allow subjects to view the different stimuli (see Figure 3). Different emotional stimuli were presented as follows: the dog's owner; an unknown person; an unfamiliar dog with agonistic approach behaviour; and a cat. Tail wagging was analysed frame by frame from video footages recorded through a video camera placed on the ceiling of the box (see Figure 3).

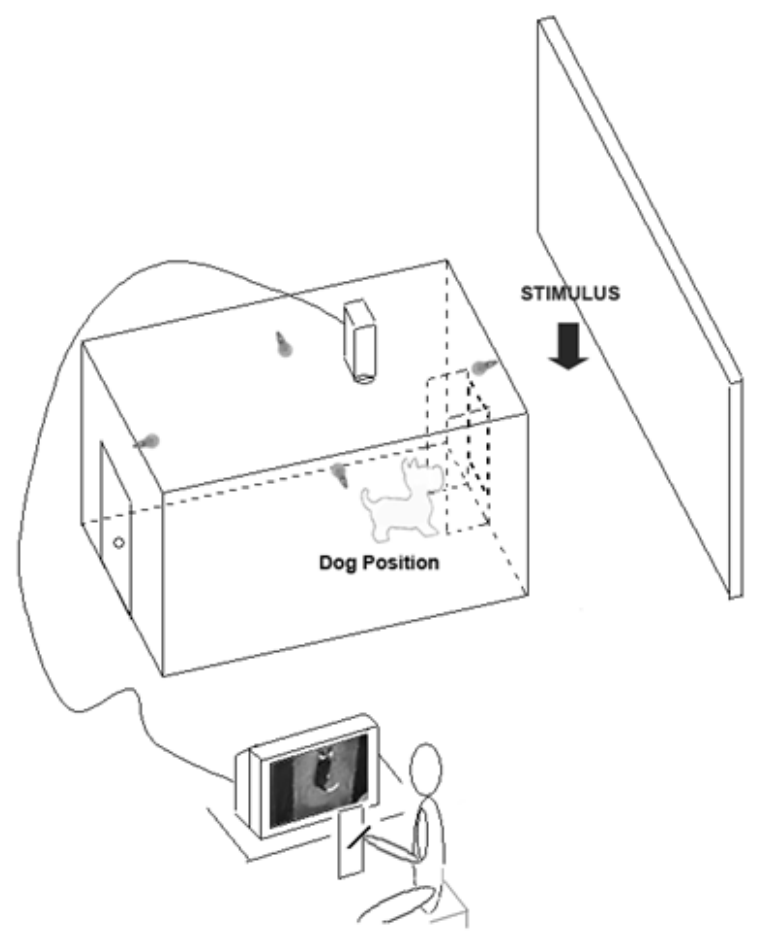

Figure 3. Schematic representation of the testing apparatus used to study asymmetric tail-wagging behaviour. 
Results revealed that both direction and amplitude of tail wagging movements were related to the emotional valence of the stimulus. Specifically, when dogs looked at stimuli with a positive emotional valence (e.g., their owner), there was a higher amplitude of tail wagging to the right. On the other hand, during presentation of negative emotional stimuli (an unfamiliar dog with a clear agonistic behaviour), a left bias in tail wagging appeared. Given that the movement of the tail depends on the contralateral side of the brain [84], results are consistent with Davidson's laterality-valence hypothesis about the specialization of the left hemisphere for the control of approaching behavioural responses (right-wag $\rightarrow$ positive stimulus) and the dominant role of the right hemisphere for the control of withdrawal responses (left-wag $\rightarrow$ negative stimulus) [85]. In dogs, similar results were reported in the work of Racca et al. [86] in which subjects presented with pictures of expressive dog faces exhibited a left gaze bias (right hemisphere activation) while looking at negative conspecific facial expressions and a right gaze bias (left hemisphere activation) when looking at positive ones. The amplitude of tail-wagging movements is also a determinant cue for estimating "quantitatively" the level of arousal elicited by different emotional stimuli: during presentations of an unfamiliar human being, dogs significantly wagged their tails to the right side of their bodies but with less amplitude than towards the owner, whereas the sight of a cat once again elicited right side tail-wagging movements with less amplitude than towards the unfamiliar human being. The right side tail-wagging bias observed during cat presentations would probably reflect the tendency of dogs to approach the stimulus under the left hemisphere control of prey-drive behaviour.

In order to test whether or not dogs detect this asymmetry, in a more recent experiment, $43 \mathrm{dogs}$ of various breeds were shown movies of other dogs or black silhouettes manipulated in order to display prevalent right or left sided tail-wagging or no wagging at all [87]. In addition, dogs' emotional response to movies was evaluated by measuring subjects' behaviour and cardiac activity. Results revealed that when dogs saw movies of a conspecific exhibiting prevalent left sided tail wagging, they had an increased cardiac activity and higher stress behaviours. Moreover, when observing movies of conspecific with right-sided tail wagging movements, dogs exhibited more relaxed behaviours with a normal cardiac activity (i.e., heart rate values similar to those of the dogs during resting) suggesting that the canine species is sensitive to the asymmetric tail movement of conspecifics, which has direct implication for understanding dog social behaviour. Different results were reported in a previous study in which the approach behaviour of free-ranging dogs to the asymmetric tail wagging of a life-size robotic dog replica was recorded [88]. Results revealed a preference to approach the robotic model (i.e., without stopping) when its tail was wagging to the left side. Authors reported that a possible explanation for the stop response during the approach to the model moving its tail with a clear bias to the right may originate when tested dogs are presented with a signal that would otherwise be positive (right wag) yet is not accompanied by additional reciprocal visual or acoustical responses by the robotic model. Another possible explanation for the different results between the two experiments is that, in the first experiment, tail movements were taken by real dogs (i.e., biological movements) while in the second they were artificially reproduced by a robotic model (even in the presence of a good dog-replica robotic movements are not properly biological).

\section{Conclusions}

Overall, there is clear evidence that functional lateralization has profound connections with cognition in dogs. A greater understanding of this association may certainly contribute to improve dog welfare and the relationship between dogs and humans. Non-invasive techniques of measuring lateralization (e.g., paw preference or tail wagging) could constitute a reliable, simple and direct tool of evaluating dogs' cognitive style and emotional affective states, providing elements that could enhance every-day management practice and improve both dogs' welfare and behavioural medicine.

Acknowledgments: All sources of funding of the study should be disclosed. Please clearly indicate grants that you have received in support of your research work. Clearly state if you received funds for covering the costs to publish in open access. 
Author Contributions: The authors contributed equally to this manuscript. There were no founding sponsors that had any role in the writing of this manuscript or in any other capacity in preparing and publishing this manuscript.

Conflicts of Interest: The authors declare no conflict of interest.

\section{References}

1. Rogers, L.J.; Andrew, R.J. Comparative Vertebrate Lateralization; Cambridge University Press: New York, NY, USA, 2002; p. 660. ISBN: 0521781612.

2. Rogers, L.J.; Vallortigara, G.; Andrew, R.J. Divided Brains. The Biology and Behaviour of Brain Asymmetries; Cambridge University Press: New York, NY, USA, 2013; p. 229. ISBN: 0521604850.

3. MacNeilage, P.F.; Rogers, L.J.; Vallortigara, G. Origins of the left and right brain. Sci. Am. 2009, 301, 60-67. [CrossRef] [PubMed]

4. Rogers, L.J. Relevance of brain and behavioural lateralization to animal welfare. Appl. Anim. Behav. Sci. 2010, 127, 1-11. [CrossRef]

5. Siniscalchi, M.; Sasso, R.; Pepe, A.M.; Vallortigara, G.; Quaranta, A. Dogs turn left to emotional stimuli. Behav. Brain Res. 2010, 208, 516-521. [CrossRef] [PubMed]

6. Siniscalchi, M.; Quaranta, A.; Rogers, L.J. Hemispheric specialization in dogs for processing different acoustic stimuli. PLoS ONE 2008, 3, e3349. [CrossRef] [PubMed]

7. Reinholz-Trojan, A.; Włodarczyk, E.; Trojan, M.; Kulczyński, A.; Stefańska, J. Hemispheric specialization in domestic dogs (Canis familiaris) for processing different types of acoustic stimuli. Behav. Process. 2012, 91, 202-205. [CrossRef] [PubMed]

8. Ratcliffe, V.F.; Reby, D. Orienting asymmetries in dogs' responses to different communicatory components of human speech. Curr. Biol. 2014, 24, 2908-2912. [CrossRef] [PubMed]

9. Andics, A.; Gácsi, M.; Faragó, T.; Kis, A.; Miklósi, A. Voice-sensitive regions in the dog and human brain are revealed by comparative fMRI. Curr. Biol. 2014, 24, 574-578. [CrossRef] [PubMed]

10. Andics, A.; Gábor, A.; Gácsi, M.; Faragó, T.; Szabó, D.; Miklósi, A. Neural mechanisms for lexical processing in dogs. Science 2016, 353, 1030-1032. [CrossRef] [PubMed]

11. Siniscalchi, M.; Sasso, R.; Pepe, A.M.; Dimatteo, S.; Vallortigara, G.; Quaranta, A. Sniffing with right nostril: Lateralization of response to odour stimuli by dogs. Anim. Behav. 2011, 82, 399-404. [CrossRef]

12. Siniscalchi, M.; d'Ingeo, S.; Quaranta, A. The dog nose "KNOWS" fear: Asymmetric nostril use during sniffing at canine and human emotional stimuli. Behav. Brain Res. 2016, 304, 34-41. [CrossRef] [PubMed]

13. LoBue, V.; DeLoache, J.S. Detecting the snake in the grass: Attention to fear relevant stimuli by adults and young children. Psychol. Sci. 2008, 19, 284-289. [CrossRef] [PubMed]

14. Fogle, B. The Dog's Mind. Pelham Editions: London, UK, 1992; p. 203. ISBN: 072071964X.

15. Wittling, W. Brain asymmetry in the control of autonomic-physiologic activity. In Brain Asymmetry; Davidson, R.J., Hugdahl, K, Eds.; MIT Press: Cambridge, UK, 1995; pp. 305-357. ISBN: 9780262041447.

16. Siniscalchi, M.; Franchini, D.; Pepe, A.M.; Sasso, R.; Dimatteo, S.; Vallortigara, G.; Quaranta, A. Volumetric assessment of cerebral asymmetries in dogs. Laterality 2011, 16, 528-536. [CrossRef] [PubMed]

17. Tan, U.; Caliskan, S. Allometry and asymmetry in the dog brain: The right-hemisphere is heavier regardless of paw preferences. Int. J. Neurosci. 1987, 35, 189-194. [CrossRef] [PubMed]

18. Rogers, L.J. Evolution of hemispheric specialisation: Advantages and disadvantages. Brain Lang. 2000, 73, 236-253. [CrossRef] [PubMed]

19. Dharmaretnam, M.; Rogers, L.J. Hemispheric specialization and dual processing in strongly versus weakly lateralized chicks. Behav. Brain Res. 2005, 162, 62-70. [CrossRef] [PubMed]

20. Lippolis, G.; Bisazza, A.; Rogers, L.J.; Vallortigara, G. Lateralization of predator avoidance responses in three species of toads. Laterality 2002, 7, 163-183. [CrossRef] [PubMed]

21. Austin, N.P.; Rogers, L.J. Asymmetry of flight and escape turning responses in horses. Laterality 2007, 12, 464-474. [CrossRef] [PubMed]

22. Scheumann, M.; Zimmermann, E. Sex-specific asymmetries in communication sound perception are not related to hand preference in an early primate. BMC Biol. 2008, 6, 3. [CrossRef] [PubMed]

23. Poremba, A.; Malloy, M.; Saunders, R.C.; Carson, R.E.; Herscovitch, P.; Mishkin, M. Species-specific calls evoke asymmetric activity in the monkey's temporal lobes. Nature 2004, 427, 448-451. [CrossRef] [PubMed] 
24. Basile, M.; Boivin, S.; Boutin, A.; Blois-Heulin, C.; Hausberger, M.; Lemasson, A. Socially dependent auditory laterality in domestic horses (Equus caballus). Anim. Cogn. 2009, 12, 611-619. [CrossRef] [PubMed]

25. Siniscalchi, M.; Laddago, S.; Quaranta, A. Auditory lateralization of conspecific and heterospecific vocalizations in cats. Laterality 2016, 21, 215-227. [CrossRef] [PubMed]

26. Böye, M.; Güntürkün, O.; Vauclair, J. Right ear advantage for conspecific calls in adults and subadults, but not infants, California sea lions (Zalophus californianus): Hemispheric specialization for communication? Eur. J. Neurosci. 2005, 21, 1727-1732. [CrossRef] [PubMed]

27. Siniscalchi, M.; Lusito, R.; Sasso, R.; Quaranta, A. Are temporal features crucial acoustic cues in dog vocal recognition? Anim. Cogn. 2012, 15, 815-821. [CrossRef] [PubMed]

28. Siniscalchi, M. Olfactory lateralization. In Lateralized Brain Functions; Rogers, L.J., Vallortigara, G., Eds.; Humana press: New York, NY, USA, 2017; pp. 103-120. ISBN: 9781493967230.

29. Siniscalchi, M. Olfaction and the Canine Brain. In Canine Olfaction Science and Law; Jezierski, T., Ensminger, J., Papet, L.E., Eds.; CRC Press: Boca Raton, FL, USA, 2016; pp. 31-37. ISBN: 1482260239.

30. Vallortigara, G.; Chiandetti, C.; Sovrano, V.A. Brain asymmetry (animal). WIREs Cogn. Sci. 2011, 2, $146-157$. [CrossRef] [PubMed]

31. Vallortigara, G. Comparative neuropsychology of the dual brain: A stroll through left and right animals' perceptual worlds. Brain Lang. 2000, 73, 189-219. [CrossRef] [PubMed]

32. Güntürkün, O.; Kesh, S. Visual lateralization during feeding in pigeons. Behav. Neurosci. 1987, 101, $433-435$. [CrossRef] [PubMed]

33. Ventolini, N.; Ferrero, E.A.; Sponza, S.; Chiesa, A.D.; Zucca, P.; Vallortigara, G. Laterality in the wild: Preferential hemifield use during predatory and sexual behaviour in the black-winged stilt. Anim. Behav. 2005, 69, 1077-1084. [CrossRef]

34. Robins, A.; Rogers, L.J. Lateralised prey catching responses in the toad (Bufo marinus): Analysis of complex visual stimuli. Anim. Behav. 2004, 68, 567-575. [CrossRef]

35. Rogers, L.J. Early experiential effects on laterality: Research on chicks has relevance to other species. Laterality 1997, 2, 199-219. [CrossRef] [PubMed]

36. Siniscalchi, M.; Pergola, G.; Quaranta, A. Detour behaviour in attack-trained dogs: Left-turners perform better than right-turners. Laterality 2013, 18, 282-293. [CrossRef] [PubMed]

37. Tan, U. Paw preferences in dogs. Int. J. Neurosci. 1987, 32, 825-829. [CrossRef] [PubMed]

38. Quaranta, A.; Siniscalchi, M.; Frate, A.; Vallortigara, G. Paw preference in dogs: Relations between lateralised behaviour and immunity. Behav. Brain Res. 2004, 153, 521-525. [CrossRef] [PubMed]

39. Poyser, F.; Caldwell, C.; Cobba, M. Dog paw preference shows liability and sex differences. Behav. Process. 2006, 73, 216-221. [CrossRef] [PubMed]

40. Batt, L.S.; Batt, M.S.; McGreevy, P.D. Two tests for motor laterality in dogs. J. Vet. Behav. 2007, 2, 47-51. [CrossRef]

41. Batt, L.S.; Batt, M.S.; Baguley, J.A.; McGreevy, P.D. Stability of motor lateralisation in maturing dogs. Laterality 2008, 13, 468-479. [CrossRef] [PubMed]

42. Batt, L.S.; Batt, M.S.; Baguley, J.A.; McGreevy, P.D. The relationships between motor lateralization, salivary cortisol concentrations and behavior in dogs. J. Vet. Behav. 2009, 4, 216-222. [CrossRef]

43. Wells, D.L. Lateralised behaviour in the domestic dog, Canis familiaris. Behav. Process. 2003, 61, $27-35$. [CrossRef]

44. Aydınlıŏlu, A.; Arslan, K.; Cengiz, N.; Ragbetli, M.; Erdoğan, E. The relationships of dog hippocampus to sex and paw preference. Int. J. Neurosci. 2006, 116, 77-88. [CrossRef] [PubMed]

45. Aydınlığlu, A.; Arslan, K.; Rıza Erdoğan, A.; Cetin Rağbetli, M.; Keleş, P.; Diyarbakırlı, S. The relationship of callosal anatomy to paw preference in dogs. Eur. J. Morphol. 2000, 38, 128-133. [CrossRef]

46. Branson, N.J.; Rogers, L.J. Relationship between paw preference strength and noise phobia in Canis familiaris. J. Comp. Psychol. 2006, 120, 176-183. [CrossRef] [PubMed]

47. McGreevy, P.D.; Brueckner, A.; Branson, N.J. Motor laterality in four breeds of dog. J. Vet. Behav. 2010, 5, 318-323. [CrossRef]

48. Wells, D.L.; Hepper, P.G.; Milligan, A.D.; Barnard, S. Comparing lateral bias in dogs and humans using the Kong ${ }^{\mathrm{TM}}$ ball test. Appl. Anim. Behav. Sci. 2016, 176, 70-76. [CrossRef]

49. Tomkins, L.M.; Thomson, P.C.; McGreevy, P.D. First-stepping Test as a measure of motor laterality in dogs (Canis familiaris). J. Vet. Behav. 2010, 5, 247-255. [CrossRef] 
50. Schneider, L.A.; Delfabbro, P.H.; Burns, N.R. Temperament and lateralization in the domestic dog (Canis familiaris). J. Vet. Behav. 2013, 8, 124-134. [CrossRef]

51. Van Alphen, A.; Bosse, T.; Frank, I.; Jonker, C.M.; Koeman, F. Paw preference correlates to task performance in dogs. In 27th Annual Conference of the Cognitive Science Society; Cognitive Science Society: Stresa, Italy, 2005; pp. 2248-2253.

52. Hackert, R.; Maes, L.D.; Herbin, M.; Libourel, P.A.; Abourachid, A. Limb preference in the gallop of dogs and the halfbound of pikas on flat ground. Laterality 2008, 13, 310-319. [CrossRef] [PubMed]

53. Gough, W.; McGuire, B. Urinary posture and motor laterality in dogs (Canis lupus familiaris) at two shelters. Appl. Anim. Behav. Sci. 2015, 168, 61-70. [CrossRef]

54. McManus, I.C. Right Hand, Left Hand: The Origins of Asymmetry in Brains, Bodies, Atoms, and Cultures; Weidenfeld \& Nicolson: London, UK, 2002; ISBN: 9780674016132.

55. Diamond, A.C.; McGrew, W.C. True handedness in the cotton-top tamarin (Saguinus oedipus)? Primates 1994, 35, 69-77. [CrossRef]

56. Laska, M. Manual laterality in spider monkeys (Ateles geoffroyi) solving visually and tactually guided food-reaching tasks. Cortex 1996, 32, 717-726. [CrossRef]

57. Güven, M.; Elalmis, D.D.; Binokay, S.; Tan, U. Population-level right-paw preference in rats assessed by a new computerized food-reaching test. Int. J. Neurosci. 2003, 113, 1675-1689. [CrossRef] [PubMed]

58. Clapham, P.J.; Leimkuhler, E.; Gray, B.K.; Mattila, D.K. Do humpback whales exhibit lateralized behaviour? Anim. Behav. 1995, 50, 73-82. [CrossRef]

59. Bisazza, A.; Cantalupo, C.; Robins, A.; Rogers, L.J.; Vallortigara, G. Right-pawedness in toads. Nature 1996, 379, 408. [CrossRef]

60. Hook, M.A.; Rogers, L.J. Development of hand preferences in marmosets (Callithrix jacchus) and effects of ageing. J. Comp. Psychol. 2000, 114, 263-271. [CrossRef] [PubMed]

61. Anderson, D.M.; Murray, L.W. Sheep laterality. Laterality 2013, 18, 179-193. [CrossRef] [PubMed]

62. Morgante, M.; Gianesella, M.; Versace, E.; Contalbrigo, L.; Casella, S.; Cannizzo, C.; Piccione, G.; Stelletta, C. Preliminary study on metabolic profile of pregnant and non pregnant ewes with high or low degree of behavioral lateralization. Anim. Sci. J. 2010, 81, 722-730. [CrossRef] [PubMed]

63. Pike, A.V.L.; Maitland, D.P. Paw preferences in cats (Felis silvestris catus) living in a household environment. Behav. Process. 1997, 39, 241-247. [CrossRef]

64. Austin, N.P.; Rogers, L.J. Limb preferences and lateralization of aggression, reactivity and vigilance in feral horses, Equus caballus. Anim. Behav. 2012, 83, 239-247. [CrossRef]

65. Austin, N.P.; Rogers, L.J. Lateralization of agonistic and vigilance responses in Przewalski horses (Equus przewalskii). Appl. Anim. Behav. Sci. 2014, 151, 43-50. [CrossRef]

66. Hook, M.A.; Rogers, L.J. Visuospatial reaching preferences of common marmosets (Callithrix jacchus): An assessment of individual biases across a variety of tasks. J. Comp. Psychol. 2008, 122, 41-51. [CrossRef] [PubMed]

67. Fagot, J.; Vauclair, J. Manual laterality in nonhuman primates: A distinction between handedness and manual specialization. Psychol. Bull. 1991, 109, 76-89. [CrossRef] [PubMed]

68. Wells, D.L.; Millsopp, S. Lateralized behaviour in the domestic cat, Felis silvestris catus. Anim. Behav. 2009, 78, 537-541. [CrossRef]

69. Versace, E.; Morgante, M.; Pulina, G.; Vallortigara, G. Behavioural lateralization in sheep (Ovis aries). Behav. Brain Res. 2007, 184, 72-80. [CrossRef] [PubMed]

70. Braccini, S.N.; Caine, N.G. Hand preference predicts reactions to novel foods and predators in marmosets (Callithrix geoffroyi). J. Comp. Psychol. 2009, 123, 18. [CrossRef] [PubMed]

71. Rogers, L.J. Hand and paw preferences in relation to the lateralized brain. Philos. Trans. R. Soc. B 2009, 364, 943-954. [CrossRef] [PubMed]

72. Hopkins, W.D.; Bennett, A.J. Handedness and approach-avoidance behaviour in chimpanzees (Pan troglodytes). J. Exp. Psychol. 1994, 20, 413-418. [CrossRef]

73. Cameron, R.; Rogers, L.J. Hand preference of the common marmoset, problem solving and responses in a novel setting. J. Comp. Psychol. 1999, 113, 149-157. [CrossRef]

74. Gordon, D.J.; Rogers, L.J. Differences in social and vocal behavior between left- and right-handed common marmosets. J. Comp. Psychol. 2010, 124, 402-411. [CrossRef] [PubMed] 
75. Gordon, D.J.; Rogers, L.J. Cognitive bias, hand preference and welfare of common marmosets. Behav. Brain Res. 2015, 287, 100-108. [CrossRef] [PubMed]

76. Marshall-Pescini, S.; Barnard, S.; Branson, N.J.; Valsecchi, P. The effect of preferential paw usage on dogs' (Canis familiaris) performance in a manipulative problem-solving task. Behav. Process. 2013, 100, 40-43. [CrossRef] [PubMed]

77. Tomkins, L.M.; Thomson, P.C.; McGreevy, P.D. Associations between motor, sensory and structural lateralisation and guide dog success. Vet. J. 2012, 192, 359-367. [CrossRef] [PubMed]

78. Siniscalchi, M.; Bertino, D.; Quaranta, A. Laterality and performance of agility-trained dogs. Laterality 2014, 19, 219-234. [CrossRef] [PubMed]

79. Siniscalchi, M.; d'Ingeo, S.; Fornelli, S.; Quaranta, A. Relationship between visuospatial attention and paw preference in dogs. Sci. Rep. 2016, 6, 31682. [CrossRef] [PubMed]

80. Quaranta, A.; Siniscalchi, M.; Frate, A.; Iacoviello, R.; Buonavoglia, C.; Vallortigara, G. Lateralised behaviour and immune response in dogs: relations between paw preference and interferon-gamma, interleukin-10 and IgG antibodies production. Behav. Brain Res. 2006, 166, 236-240. [CrossRef] [PubMed]

81. Quaranta, A.; Siniscalchi, M.; Albrizio, M.; Volpe, S.; Buonavoglia, C.; Vallortigara, G. Influence of behavioural lateralization on interleukin-2 and interleukin- 6 gene expression in dogs before and after immunization with rabies vaccine. Behav. Brain Res. 2008, 186, 256-260. [CrossRef] [PubMed]

82. Siniscalchi, M.; Sasso, R.; Pepe, A.M.; Dimatteo, S.; Vallortigara, G.; Quaranta, A. Catecholamine plasma levels following immune stimulation with rabies vaccine in dogs selected for their paw preferences. Neurosci. Lett. 2010, 476, 142-145. [CrossRef] [PubMed]

83. Quaranta, A.; Siniscalchi, M.; Vallortigara, G. Asymmetric tail-wagging responses by dogs to different emotive stimuli. Curr. Biol. 2007, 17, R199-R201. [CrossRef] [PubMed]

84. Buxton, D.F.; Goodman, D.C. Motor function and the corticospinal tracts in the dog and raccoon. J. Comp. Neurol. 1967, 129, 341-360. [CrossRef] [PubMed]

85. Davidson, R.J. Well-being and affective style: Neural substrates and biobehavioural correlates. Phil. Trans. R. Soc. B 2004, 359, 1395-1411. [CrossRef] [PubMed]

86. Racca, A.; Guo, K.; Meints, K.; Mills, D.S. Reading faces: differential lateral gaze bias in processing canine and human facial expressions in dogs and 4-year-old children. PLoS ONE 2012, 7, e36076. [CrossRef] [PubMed]

87. Siniscalchi, M.; Lusito, R.; Vallortigara, G.; Quaranta, A. Seeing left- or right-asymmetric tail wagging produces different emotional responses in dogs. Curr. Biol. 2013, 23, 2279-2282. [CrossRef] [PubMed]

88. Artelle, K.A.; Dumoulin, L.K.; Reimchen, T.E. Behavioral responses of dogs to asymmetrical tail wagging of a robotic dog replica. Laterality 2011, 16, 129-135. [CrossRef] [PubMed] 